\title{
Environmental Governance Effect of the Transformation of Export Trade Mode: Empirical Evidence from 194 Cities in China
}

guangqin Li ( $\square$ zjfcligq@126.com )

Anhui University of Finance and Economics https://orcid.org/0000-0002-2938-5392

\section{Xubing Fang}

Anhui University of Finance and Economics

Maotao Liu

Anhui University of Finance and Economics

\section{Research Article}

Keywords: Transformation of Export Trade Mode, Environmental Pollution, PM2.5 Concentration, Threshold Effect

Posted Date: September 27th, 2021

DOl: https://doi.org/10.21203/rs.3.rs-815768/v1

License: (9) This work is licensed under a Creative Commons Attribution 4.0 International License. Read Full License

Version of Record: A version of this preprint was published at Environmental Science and Pollution Research on November 19th, 2021. See the published version at https://doi.org/10.1007/s11356-02117110-4. 
2 Trade Mode: Empirical Evidence from 194 Cities in China

3

4 Guangqin $\mathrm{Li}^{*}$ : A professor, $\mathrm{PhD}$

5 School of International Trade \& Economics, Anhui University of Finance \&

6 Economics, Bengbu, Anhui 233030 China

7 Email: zjfcligq@126.con (the corresponding author)

Xubing Fang: MA

School of International Trade \& Economics, Anhui University of Finance \& Economics, Bengbu, Anhui 233030 China

Email: fangxb1026@126.com

Maotao Liu: MA

School of Finance, Anhui University of Finance \& Economics, Bengbu, Anhui 233030 China

Email: 2514306153@qq.com

Funding

We acknowledge the financial support from the University Research Project of Anhui University of Finance and Economics (Research on the Green Development Effect of China's Green Credit Policy) and the Graduate Research Innovation Fund of Anhui University of Finance and Economics (ACYC2019039; ACYC2019114).

\section{Acknowledgments}

Author gratitude is extended to the prospective editor(s) and reviewers that will/have spared time to guide toward a successful publication.

Authors' contributions

The first author (Dr Guangqin Li) is responsible for the design and first draft of the study. The second author (Dr Xubing Fang) is responsible for the first draft and translation, the third authors (Dr Maotao Liu) is responsible for data processing and literature collection.

Data Availability

After the paper is published, the data will be shared on the public data platform (https://dataverse.harvard.edu)。 
38

39

40

41

42

43

44

45

46

47

48

49

50

51

52

53

Ethical approval

Authors mentioned in the manuscript have agreed for authorship read and approved the manuscript, and given consent for submission and subsequent publication of the manuscript.

\section{Consent to participate}

Note Applicable

Consent to publish

Applicable

Competing interests

I wish to disclose here that there are no potential conflicts of interest at any level of this study. 


\title{
Environmental governance effect of the Transformation of Export
}

\section{Trade Mode: Empirical Evidence from 194 Cities in China}

\begin{abstract}
As one of the developing countries, China's export trade mode (ETM) has gradually shifted from processing trade to general trade. Is the deterioration of China's environmental pollution caused by the transformation of ETM? Based on the panel data from 194 cities in China from 2000 to 2016, this paper investigates the impact of ETM transformation on the environmental pollution and its internal mechanism. The results show that: the ETM is gradually shifting from processing trade to general trade, environmental pollution will deteriorate first and then improve, that is, showing a significant "inverted U-shaped" relationship between the transformation of ETM and environmental pollution. Through the robustness test of the threshold, and SYS-GMM model, the results are still valid. The mechanism research shows that the upgrading of industrial structure, energy structure, industrial agglomeration, environmental protection investment and resource allocation are the main mechanism that the transformation of ETM affect environmental pollution. The conclusions of this study can provide empirical evidence for the process that the environmental pollution level of developing countries deteriorated and then improved during the process of transforming from processing export trade to general export trade.
\end{abstract}

Key words: Transformation of Export Trade Mode; Environmental Pollution; PM2.5 Concentration; Threshold Effect 


\section{Introduction}

As the largest developing country in the world, China's foreign trade has been accompanied by rapid economic growth in the past 40 years. Behind the ever-increasing economic aggregate, China suffers from environmental pollution to varying degrees. In 2013, the outbreak of severe smog pollution caused China's environmental problems to attract domestic and foreign attention, but in recent years, the degree of environmental pollution has been greatly improved. According to the Statistical Bulletin of China's Ecological Environment in 2020, the air quality of 202 cities above 337 prefecture-level cities in China reached the standard, accounting for $59.9 \%$, while the proportion was $24.9 \%$ in 2016, which decreased by 35 percentage points in four years. In the "14th Five-Year Plan and Outline of Long-term Goals for 2035", China clearly emphasizes "to speed up the development of green transformation mode and continuously improve environmental quality" to realize the green transformation and upgrading of China's economy. Therefore, it is of great theoretical and practical significance to study China's green transformation and its main transformation modes for China's environmental pollution control and high-quality economic development. In theory, many scholars explain environmental pollution from urbanization (Khan et al., 2021; Koyuncu et al., 2021), economic growth (Xie and Liu, 2019; Asiedu et al., 2021), FDI (Sabir et al., 2020), financial development (Chien et al., 2021; Ye et al., 2021), energy consumption (Zafar, 2020; Jun et al., 2021). Under the support of the "Trade Power" strategy, China's export trade continues to expand. Compared with the above factors, the impact of export trade on environmental pollution should be paid attention to. According to statistics, China's total export trade rose 1070 times in 2020 compared with 1978. Despite the severe and complex international situation in the past two years, and the serious impact of the 2019-new coronavirus (2019-nCoV), China's export of goods still shows a positive growth trend. As the share of general export trade continues to expand, China has gradually formed an export trade model integrating processing trade and general trade into the global value chain (Yi, 2003). Therefore, does the transformation in China's export trade mode (ETM) worsen or improve environmental pollution? How to effectively achieve the "winwin" goal of export trade development and environmental protection?

Since 1990, the trade patterns of various countries have changed with the acceleration of economic globalization, and the expansion of trade scale has further promoted technological innovation and economic growth (Figueiredo et al., 2020). Economic growth is often accompanied by environmental pollution. In the context of the rapid advancement of trade globalization and the severe deterioration of the environment, trade and the environment have always been the research hotspots of scholars. There are many studies discussing the impact of trade on environmental pollution (Essandoh et al., 2020), which can be summarized into the following three aspects: first, trade has deteriorated the environment (Al-mulal, 2012; Yu et al., 2019; He et al., 2020). Most studies use $\mathrm{CO} 2$ emissions to characterize environmental quality, and believe that trade liberalization has a negative effect on environmental quality. Second, trade has improved the environment (Shahbaz et al., 2012; Dean, 2002; Kim et al., 2019). For the research in China, Xu et 
al. (2020) used panel data from 279 prefecture-level cities and found that trade liberalization significantly reduced PM2.5. Third, the relationship between trade and environmental pollution is unclear (Al-Mulali et al., 2015; Xie and Wu, 2021). Shahbaz et al. (2017) researched that the combined effects of trade openness can help improve environmental quality, while the comparative advantage effect will worsen environmental quality.

The existing literature on the environmental effects of trade mostly focuses on trade opening, trade liberalization, etc., without considering the important issue of ETM transformation. Processing trade and general trade, which are based on the international division of production, have different impacts on environmental pollution. Moreover, under the background of international division of labor, how does the transformation of ETM promoted by general export trade affect environmental pollution? Under the above background, exploring the impact of the change of ETM on environmental pollution and its transmission mechanism has important academic value and practical significance for the change of ETM and environmental pollution control in China and even other developing countries.

In view of this, this study took 194 cities in China from 2000 to 2016 as the research object, uses the PM2.5 concentration value from satellite remote sensing data, and the Chinese customs database to calculate the general trade volume and processing trade of each city, to systematically investigate the impact of ETM transformation on environmental pollution and its internal mechanism. The possible marginal contributions of this paper are as follows: Firstly, based on the novel perspective of ETM transformation, the paper empirically examines the relationship between the transformation of ETM and environmental pollution, enriching the related research on trade and environment; Secondly, based on city data, this paper can more accurately identify the non-linear relationship between the transformation of ETM and environmental pollution; Thirdly, this paper applies the intermediary effect model to the nonlinear model to investigate the intermediary effect of ETM transformation, which enriches the application of intermediary effect model to extend to nonlinear model.

The structure of this paper is as follows: the second part is literature review and theoretical hypotheses; the third part is research design; the fourth part is empirical results and analysis; the fifth part is further analysis; the last part is the main conclusions and policy suggestion.

\section{Theoretical Analysis and Research Hypothesis}

At present, the academic research on trade and environmental pollution is mainly based on the following three theories: First is the "pollution shelter" hypothesis (PHH). In order to promote their economic development and reduce environmental pollution, developed countries usually transfer low-end manufacturing industries with "high pollution and high energy consumption" to developing countries with relatively weak environmental regulations; in addition, the increase in external demand will expand the export trade volume of developing countries, resulting in developing countries eventually using their own resource consumption and environmental pollution in exchange for economic development. Second is the "Environmental Kuznets Curve" hypothesis (EKC). The 
theory holds that there is an "inverted U-shaped" curve relationship between the degree of environmental pollution and the level of per capita income. On the left side of the turning point, although economic development increases income, the initial economic development is at the expense of the environment; when the level of per capita income exceeds the turning point, highlevel income improves the quality of life of the general public. Residents' high requirements for environmental quality will prompt them to pay more to improve environmental quality. Third is "the theory of environmental trade effect". The theory mainly includes three aspects: scale effect, structure effect and technology effect (Copeland and Taylor, 1994). The scale effect is that trade liberalization promotes economic growth by expanding the scale of production, but the low-end and backward mode of production aggravates environmental pollution, with the development of international trade. In addition, scale effect will indirectly enhance public awareness of environmental protection through the increase of total economic output, and then improve environmental quality. The structural effect is that the detailed international division of labor strengthens the cooperation among the participating countries, and in this context, the trade structure of various countries will change due to the effect of trade comparative advantage. Therefore, the impact of trade structure effect on the environment is as follows: if a country has a comparative advantage of clean products, trade will improve the environment; if it has a comparative advantage in pollution-intensive sectors, trade will worsen the environment. The effect of technology is that the expanded division of labor and economies of scale caused by trade liberalization have improved the efficiency of the use of factor resources; international trade has promoted the mutual infiltration and global flow of advanced technologies, improving global environmental pollution; and trade has promoted economic growth. The income level of various countries has increased, and the demand for green products has increased, which has indirectly improved the environmental quality.

In the process of participating in the global division of labor, developing countries initially participated in the global division of labor system through the processing trade of processing trade and compensation trade. With the gradual establishment of the production capacity and industrial system of the developing countries, the developed countries will transfer the links of environmental regulation in their production to the developing countries, and the developing countries will become the "pollution havens" of the developed countries. At this time, the deep processing industry in developing countries can develop, but these enterprises have the characteristics of high energy consumption, serious pollution and low level of production technology. As the level of deep processing in developing countries continues to improve, they begin to engage in general trade aimed at the export of final consumer goods. In the global division of labor system, developing countries begin to rise from the low end of the global value chain to both ends, but the high-end link of the global value chain is still restricted by developed countries. At this time, the scale effect and structural effect will lead to increasingly serious environmental pollution in developing countries. With the development of deep processing trade and general trade in developing countries, the developing countries have formed their own industrial system, especially the introduction and transformation of advanced technology and equipment from developed countries, and enhance the 
status of the global value chain through technological innovation. The "technological innovation effect" began to play a leading role, and the negative impact of trade on the environment gradually changed into a positive effect.

To sum up, in the initial stage of the development of export trade, the proportion of general trade is small. With the increase of the proportion of processing trade, the ETM based on processing trade will aggravate environmental pollution. With the further change of ETM, especially the state attaches importance to environmental protection and restricts enterprises with high pollution and high energy consumption, the transformation of ETM has improved environmental pollution due to the decline in the proportion of processing trade and the increase in the proportion of general trade. At the same time, rapid economic development has improved the quality of life in developing countries. The demand preference for environmental quality has also increased, the public awareness of environmental protection has been enhanced, and the environment has been better managed. With the strengthening of environmental regulation in developing countries, low-end products will gradually lose their market in developing countries, and developing countries will achieve "green" transformation and upgrading by improving the level of technological innovation. The reverse technology spillover effects of developed countries and strict international environmental policies will promote the research and development of advanced new environmental governance technologies and improve environmental standards in developing countries. At this time, the positive effect of "technological innovation effect" on environmental pollution will be greater than the negative effect of "scale effect", and the environmental quality will be improved. Accordingly, this paper proposes the following hypothesis 1:

H1: The transformation of ETM has a non-linear "inverted U-shaped" effect on environmental pollution.

The impact mechanism of ETM transformation on environmental pollution may be analyzed from the following five aspects: Firstly, trade development not only expands the scale of trade, promotes domestic capital accumulation, but also accelerates the upgrading of industrial structure. Also, through increasing domestic consumer demand to force enterprises to carry out technological innovation, as well as learning from foreign advanced economic systems and other measures to promote the upgrading of industrial structures, industrial structure through green transformation and upgrading will help to improve environmental quality (Xu and Lin, 2015). Secondly, the development of trade with high pollution and high energy consumption will worsen the environment, but export trade will also promote the improvement of energy efficiency through "export middle schools" and "economies of scale" in the adjustment of energy structure, which will help to improve environmental quality (Melitz, 2003; Lin and Liu, 2015). Thirdly, industrial co-agglomeration is the coordinated development level of manufacturing and producer services. As an important support of economic growth, the coordinated development of the manufacturing and producer services will promote the upgrading and rationalization of the industrial structure. The upgrading and rationalization of industrial structures will reduce the proportion of polluting industries, thus promoting the improvement of environmental quality. Fourthly, with the development of general 
trade, the country's profits from trade will improve environmental technology by increasing investment in environmental protection, so as to improve environmental quality. Fifthly, the efficiency of resource allocation is the main embodiment of the efficiency of economic development. In the process from processing trade to general trade, the efficiency of labor and capital allocation will be further improved (Grossman, 2008). The improvement of the efficiency of resource allocation will make resources flow to greener and healthier industries, thus improving environmental quality (Shi et al., 2018). Accordingly, this paper proposes the following hypothesis 2 :

H2: The upgrading of industrial structure, energy structure, industrial coordination and agglomeration, environmental protection investment and resource allocation are the main ways for the transformation of export trade mode to affect environmental pollution.

\section{Research design}

\subsection{Model design}

According to $\mathrm{H} 1$, the transformation of ETM may have a non-linear relationship with environmental pollution. In this paper, the square term of ETM transformation is added to the empirical model, and the following econometric model can be constructed to examine the environmental governance effect of ETM transformation:

$$
P M 2.5_{i t}=\alpha+\beta_{1} T s_{i t}+\beta_{2} T s_{-} s q_{i t}+\gamma X_{i t}+u_{i}+v_{i}+\zeta_{i t}
$$

Among them, $i$ represents the city, $t$ represents the year; PM2.5 is the environmental pollution level; $T s$ and $T s \_s q$ represent primary term and quadratic term of transformation of ETM respectivel; $X$ is the series of factors that affect the environmental pollutiont, $\gamma$ represents the coefficient matrix of the Control variables; $\mu_{i}$ and $v_{t}$ respectively represents the city and year effects to control factors that change from time to time; $\zeta_{i t}$ is the random disturbance item. If $\beta_{2}$ is significantly negative, it indicates that there is a non-linear "inverted U-shaped" relationship between the transformation of ETM and environmental pollution; on the contrary, it shows that there is a " $\mathrm{U}$ " curve relationship between them.

\subsection{Variable definition}

\subsubsection{Explained variable}

Environmental Pollution (PM2.5): This paper selects the $\mathrm{PM}_{2.5}$ concentration value. Considering that the period for China to include $\mathrm{PM}_{2.5}$ concentration in the monitoring range is 2012 , the research time span of this paper needs to be 2000-2016, so there are a large number of missing values in the sample period. In view of this, this article refers to the research of Li et al. (2021a, 2021b), through the use of ArcGIS software technology to match the raster data of the annual average concentration of $\mathrm{PM}_{2.5}$ released by Columbia University with the administrative map of China (prefecture-level city), and parse it out the average concentration of $\mathrm{PM}_{2.5}$ in prefecture-level cities in China. The data source is satellite remote sensing monitoring data, so it can more accurately 
and reliably reflect the true situation of China's environmental pollution. In the robustness test, we also used the natural logarithm of industrial sulfur dioxide(lnso2) and industrial smoke-dust emissions (lnind-smoke) to test.

\subsubsection{Core explanatory variables}

The core explanatory variable of this paper are primary term $(T s)$ and quadratic term $\left(T s \_s q\right)$ of ETM transformation, which measured by the ratio of general trade to processing trade. This data identifies the annual export value of each trade method in each city through the region and trade mode in the Chinese customs database, and then measures the change in export trade mode by the ratio of the general trade export value to the processing trade export value.

\subsubsection{Control variables}

In addition to the core explanatory variables of ETM transformation, this paper draws on relevant literature and controls the following variables:

(1) Industrial structure (lnsecond): Measured by the proportion of the quadratic industry in GDP. Due to the large differences in the quadratic industry of each city, this paper also takes the logarithm. Since the pollutant gas produced by a large number of fossil fuels and the emission of industrial smoke-dust in the process of industrialization will aggravate environmental pollution. The expected sign is positive.

(2) Per capita GDP (lnpgdp): Measured using the natural logarithm of the actual per capita GDP. The higher the level of economic development, the higher the quality of life of the people and the increased awareness of environmental protection may improve environmental pollution. However, the increase in the level of urban economic development will also cause environmental pollution. The expected sign is uncertain.

(3) Foreign direct investment ( $f d i)$ : Measured by the actual foreign direct investment as a percentage of GDP. On the one hand, in the process of foreign investment, the country's highpolluting and high-energy-consuming industries will be transferred to areas with lower environmental regulations in China, which will intensify environmental pollution in this area and become a "pollution refuge" in other countries; on the other hand, foreign direct investment has advanced environmental governance technologies and management levels will not only directly reduce local environmental pollution, but will also enhance the production technology innovation level of Chinese enterprises through technology spillover effects and reduce environmental pollution (Shao et al., 2016). The expected sign is uncertain.

(4) Government expenditure (gov): Measured by the ratio of local government fiscal expenditure to GDP. Local fiscal expenditures are mostly used for economic development and relatively low investment in environmental protection. The expected sign is positive.

(5) Urbanization level ( $u r b)$ : Measured by the ratio of the urban non-agricultural population to the total urban population at the end of the year. On the one hand, the urbanization process will destroy the ecosystem along with the expansion of the city scale, and at the same time, will produce a large amount of environmental pollution and energy consumption; on the other hand, the increase in the level of urbanization will increase the demand of urban residents for high environmental 
quality, which will increase its environmental awareness and improve environmental pollution (Shao et al., 2019). The expected sign is uncertain.

(6) Capital to labor ratio $(\ln k l)$ : Measured by the ratio of capital stock to labor force (Shi Daqian et al., 2018). Reasonable resource allocation will promote the flow of factors to low-pollution and low-energy-consuming industries. On the one hand, industries with high pollution and high energy consumption can be eliminated and environmental pollution can be improved; on the other hand, the improvement of resource allocation efficiency will bring capital, labor, etc. The more flexible use of the elements can avoid the waste of resources to a certain extent, thereby reducing environmental pollution. The expected sign is positive.

(7) Energy structure (energy): Measured by the proportion of coal consumption in total energy consumption, the main source of environmental pollution is the polluting gas produced by coal combustion. The expected sign is positive.

(8) Environmental regulation (lneg): Measured by the natural logarithm of the investment in industrial pollution control. Increasing investment in industrial pollution control will help improve environmental pollution, the expected sign is negative.

\subsection{Data Sources and descriptive statistics}

The main sources of data used in this paper are China Customs Database, China Urban Statistics Yearbook, China Energy Statistics Yearbook and China Environmental Statistics Yearbook. Because there are a large number of cities in the China Customs Database that can not identify the values of general trade and processing trade, this paper only retains 194 cities that can identify general trade and processing trade. At present, the available Chinese customs database mainly starts from 2000, and the latest data can be until 2016. Therefore, the research samples of this paper are 3298 samples from 2000 to 2016 of 194 cities. In order to deal with the heteroscedasticity in empirical research, some variables will be logarithmic, and Table 1 reports the descriptive statistics of related variables.

\section{Table 1}

Descriptive statistics of variables

\begin{tabular}{cccccc}
\hline Variable & Obs. & Mean & S.D. & Min. & Max. \\
\hline Explained variable & & & & & \\
\hline PM 2.5 & 3298 & 38.2950 & 15.7602 & 5.3900 & 91.1600 \\
Inso2 & 3298 & 10.6016 & 1.0883 & 4.1589 & 16.8567 \\
lnind-smoke & 3298 & 9.8257 & 1.1277 & 3.8501 & 15.0094 \\
\hline Core explanatory variables & & & & \\
\hline Ts & 3298 & 5.4144 & 5.7703 & 0.4583 & 18.5714 \\
$T$ Ts_sq & 3298 & 62.6018 & 109.2198 & 0.2101 & 344.8969 \\
\hline Control variables & & & & \\
\hline lnsecond & 3298 & 3.8660 & 0.2086 & 2.9216 & 4.4965 \\
lnpgdp & 3298 & 4.2703 & 0.3400 & 3.2036 & 5.6979
\end{tabular}




\begin{tabular}{cccccc} 
fdi & 3298 & 0.0298 & 0.0301 & 0.0000 & 0.4729 \\
gov & 3298 & 0.1239 & 0.0617 & 0.0273 & 1.5000 \\
urb & 3298 & 0.6525 & 0.3439 & 0.0986 & 1.0000 \\
lnkl & 3298 & 5.5039 & 0.6173 & 2.6287 & 6.6284 \\
energy & 3298 & 0.9636 & 0.2914 & 0.3609 & 2.3060 \\
lneg & 3298 & 4.8881 & 1.1000 & 0.3716 & 7.2564 \\
\hline
\end{tabular}

\section{4. Empirical Results and Analysis}

332

333

334

335

336

337

338

339

340

341

342

343

344

345

346

347

348

349

350

351

352

353

354

355

356

357

358

359

360

361

\subsection{Benchmark regression analysis}

According to research 1 and formula (1), The table 2 is the result of benchmark regression. Columns (1) and (2) only take into account the impact of the primary term (Ts) of ETM transformation on environmental pollution. Column (3) and (4) also adds the impact of the primary $(T s)$ and quadratic $\left(T s \_s q\right)$ items of the ETM transformation on environmental pollution. The four models all control time and city fixed effects.

In columns (1) and (2) are not significant, the coefficients of the primary term of ETM transformation, which indicates that there is no linear relationship between the transformation of ETM and environmental pollution regardless of whether Control variables are added. In columns (3) and (4), the results show that the estimated coefficients of the primary and quadratic terms of ETM transformation are significant positive and negative effects respectively at the $1 \%$ statistical level, indicating that the Control variables are added or not in general, there is a significant "inverted U-shaped" relationship between the transformation of ETM and environmental pollution. Further based on the results in column (4), the turning point value of the "inverted U-shaped" curve for calculating the transformation of ETM and environmental pollution is 9.1688, indicating that the transformation of ETM is at a low level $(<9.1688)$ (that is, if there are only processing trade and general trade, the export volume of general trade accounts for less than $90 \%$ and the export volume of processing trade accounts for more than 10\%), at this time the transformation of ETM will aggravate environmental pollution; on the contrary, when the proportion of general trade in exports value exceeds $90 \%$, the transformation of ETM will significantly improve the environment. H1 was tested.

From the results in column (4), the coefficients of capital-labor ratio $(\ln k l)$, foreign direct investment (fdi), and energy structure (energy) are all significantly positive at the $1 \%$ statistical level, indicating that increasing the capital-labor ratio, increasing foreign direct investment and increasing the proportion of coal consumption will increase environmental pollution. The estimated coefficient of environmental protection investment (lneg) is significantly negative at the $1 \%$ statistical level, indicating that the increase in investment in industrial pollution control will significantly improve environmental pollution. The coefficients of industrial structure (lnsecond) and government expenditure (gov) are both positive, but not significant, indicating that the increase in the proportion of the quadratic industry in the three major industries may aggravate environmental pollution; the 
362 impact of government expenditure on environmental pollution is confirmed to a certain extent "the 363 Hypothesis of Gradually Low Competition". The estimated coefficients of per capita GDP (lnpgdp) 364 and urbanization level (urb) are negative, but still not significant. This may be explained by the 365 possible non-linear relationship between per capita GDP and urbanization level and environmental 366 pollution (Shao et al., 2019).

\section{Table 2}

368 Benchmark Regression Results.

\begin{tabular}{|c|c|c|c|c|}
\hline & \multicolumn{4}{|c|}{$P M_{2.5}$} \\
\hline & (1) & (2) & (3) & (4) \\
\hline \multirow[t]{2}{*}{$T s$} & -0.0158 & -0.0178 & $0.2926^{* * *}$ & $0.2879^{* * *}$ \\
\hline & $(0.0208)$ & $(0.0208)$ & $(0.0737)$ & $(0.0732)$ \\
\hline \multirow[t]{2}{*}{$T s \_s q$} & & & $-0.0158^{* * *}$ & $-0.0157^{* * *}$ \\
\hline & & & $(0.0036)$ & $(0.0036)$ \\
\hline \multirow[t]{2}{*}{ lnsecond } & & 0.7267 & & 0.8678 \\
\hline & & $(0.9180)$ & & $(0.9159)$ \\
\hline \multirow[t]{2}{*}{$\operatorname{lnpg} d p$} & & -0.8868 & & -0.9401 \\
\hline & & (1.2824) & & (1.2787) \\
\hline \multirow[t]{2}{*}{$\operatorname{lnkl}$} & & $3.4826^{* * *}$ & & $3.3423^{* * *}$ \\
\hline & & $(0.5839)$ & & $(0.5831)$ \\
\hline \multirow[t]{2}{*}{$f d i$} & & $12.9668^{* * *}$ & & $13.6649^{* * *}$ \\
\hline & & $(4.0433)$ & & $(4.0348)$ \\
\hline \multirow[t]{2}{*}{ lneg } & & $-0.8720^{* * *}$ & & $-0.8379^{* * *}$ \\
\hline & & $(0.2344)$ & & $(0.2339)$ \\
\hline \multirow[t]{2}{*}{ energy } & & $2.7745^{* * *}$ & & $2.9341^{* * * *}$ \\
\hline & & $(0.9087)$ & & $(0.9068)$ \\
\hline \multirow[t]{2}{*}{ gov } & & 0.6109 & & 0.7012 \\
\hline & & $(2.3232)$ & & $(2.3166)$ \\
\hline \multirow[t]{2}{*}{$u r b$} & & -1.1403 & & -1.1571 \\
\hline & & $(0.9260)$ & & $(0.9233)$ \\
\hline \multirow[t]{2}{*}{ constant } & $25.2349^{* * *}$ & $11.8065^{\text {*** }}$ & $24.6360^{* * *}$ & $11.1820^{* *}$ \\
\hline & $(0.3238)$ & $(4.5153)$ & $(0.3509)$ & $(4.5045)$ \\
\hline Observation & 3298 & 3298 & 3298 & 3298 \\
\hline F test & 253.3785 & 179.4236 & 241.7546 & 174.2549 \\
\hline$R^{2}$ & 0.5825 & 0.5930 & 0.5851 & 0.5955 \\
\hline Turning point & - & - & 9.2595 & 9.1688 \\
\hline Year FE & Yes & Yes & Yes & Yes \\
\hline Urban FE & Yes & Yes & Yes & Yes \\
\hline
\end{tabular}




\subsection{Robustness test}

In this part, three strategies will be adopted to test the robustness of the benchmark regression model, including substitution variables, one-period lag processing of control variables, and change estimation methods.

\subsubsection{Substitution the explained variable}

First, this paper will select sulfur dioxide emissions $\left(\operatorname{lnso}_{2}\right)$ and industrial smoke-dust emissions (lnind-smoke) as the substitute variables of environmental pollution $\left(P M_{2.5}\right)$ for robustness testing, and the results are reported in table 3.

The estimation results in the first two columns show that when sulfur dioxide emissions $\left(\operatorname{lns} \mathrm{S}_{2}\right)$ are used to characterize environmental pollution, the primary coefficient of ETM transformation is significantly positive and the quadratic coefficient is significantly negative, indicating that there is a significant "inverted U-shaped" relationship between the transformation of ETM and environmental pollution. Similarly, when the explained variable is industrial smoke-dust emissions (Inind-smoke), it can be seen from the results of the latter two columns that, regardless of whether the Control variables is added or not, the primary and quadraticfirst coefficients of ETM transformation are both significantly positive and negative respectively, once again verify that there is an "inverted U-shaped" relationship between the transformation of ETM and environmental pollution. In summary, the robustness test of this part is basically consistent with the previous benchmark analysis, indicating that the benchmark regression results have strong robustness. Regarding sulphur dioxide emissions and industrial smoke-dust emissions, the turning points for the transformation of ETM are around 15 and 14, respectively, indicating that for these two pollutants, the proportion of general trade exports needs to reach $94 \%$ or more, that is to say, processing trade requires below $6 \%$, the effect of environmental governance can only be achieved by the transformation of ETM.

\section{Table 3}

Substitution explained variable

\begin{tabular}{ccccc}
\hline & \multicolumn{2}{c}{ lnso $_{2}$} & \multicolumn{2}{c}{ lnind-smoke } \\
\cline { 2 - 5 } & $(1)$ & $(2)$ & $(3)$ & $(4)$ \\
\hline$T s$ & $0.0348^{* * *}$ & $0.0403^{* * *}$ & $0.0552^{* * *}$ & $0.0533^{* * *}$ \\
& $(0.0098)$ & $(0.0097)$ & $(0.0114)$ & $(0.0113)$ \\
\multirow{2}{*}{$s_{-} s q$} & $-0.0011^{* *}$ & $-0.0013^{* * *}$ & $-0.0020^{* * *}$ & $-0.0019^{* * *}$ \\
& $(0.0005)$ & $(0.0005)$ & $(0.0006)$ & $(0.0006)$ \\
constant & $9.9703^{* * *}$ & $5.8240^{* * *}$ & $9.2717^{* * *}$ & $7.4738^{* * *}$ \\
& $(0.0468)$ & $(0.5968)$ & $(0.0541)$ & $(0.6949)$ \\
\hline Observation & 3298 & 3298 & 3298 & 3298 \\
F test & 0.292 & 0.319 & 0.142 & 0.162 \\
$R^{2}$ & 70.6481 & 55.4968 & 28.3305 & 22.9519
\end{tabular}


Turning point

Control variables

15.8182

\section{No}

Year FE

Urban FE

Yes

15.5

13.8

14.0263

\subsubsection{One-period lag test}

Considering that environmental pollution is a continuous and dynamic process, the behavior in the early stage may have an impact on the current period or the lag period. The transformation of ETM and Control variables may have a lag effect. The results are shown in table 4.

The lag effect test results in table 4 show that no matter the explained variables are smog pollution $\left(P M_{2.5}\right)$, sulfur dioxide emission $\left(\right.$ lnso $\left._{2}\right)$ or industrial smoke-dust emission (Inind-smoke), the primary term of ETM transformation is positive at the $1 \%$ statistical level, and the quadratic coefficient is negative at the 5\% statistical level at least. The results show that the significant "inverted U-shaped" relationship between the transformation of ETM and environmental pollution is still valid, and the benchmark regression results have strong robustness. H1 still holds. At this point, the three turning points all increased to a certain extent, indicating that the impact of ETM transformation in the last period on the current environmental pollution will make the time lag of the turning point.

\section{Table 4}

One-period lag test

\begin{tabular}{cccc}
\hline & $P M_{2.5}$ & lnso 2 & lnind-smoke \\
\cline { 2 - 4 } & $(1)$ & $(2)$ & $(3)$ \\
\hline L.Ts & $0.2357^{* * *}$ & $0.0377^{* * *}$ & $0.0652^{* * *}$ \\
& $(0.0734)$ & $(0.0094)$ & $(0.0112)$ \\
L.Ts_sq & $-0.0123^{* * *}$ & $-0.0011^{* *}$ & $-0.0023^{* * *}$ \\
& $(0.0036)$ & $(0.0005)$ & $(0.0006)$ \\
constant & $13.2000^{* * *}$ & $7.4600^{* * *}$ & $8.6240^{* * *}$ \\
& $(4.5458)$ & $(0.5841)$ & $(0.6930)$ \\
\hline Observation & 3104 & 3104 & 3104 \\
F test & 112.4025 & 55.8484 & 22.5177 \\
$R^{2}$ & 0.4934 & 0.3261 & 0.1633 \\
Turning point & 9.5813 & 17.1364 & 14.1739 \\
Control variables & Yes & Yes & Yes \\
Year FE & Yes & Yes & Yes \\
Urban FE & Yes & Yes & Yes \\
\hline
\end{tabular}

\subsubsection{Replacement estimation method}

This part adopts SYS-GMM estimation to re-estimate the impact of ETM transformation on environmental pollution. It can be seen from table 5 that the models have passed the second-order serial correlation and sargan test, indicating that the selected instrument variables are reasonable 
and the estimates are effective. The estimation results in column (1) show that the L.PM2.5 coefficient is significantly 0.8693 at the $1 \%$ statistical level, indicating that environmental pollution has a strong path dependence. The primary and quadratic coefficients of ETM transformation are significantly 0.1409 and -0.0091 at the $1 \%$ statistical level respectively, indicating that there is an "inverted U-shaped" relationship between the transformation of ETM and environmental pollution. Similarly, the results in columns (2) and (3) also verify that there is an "inverted U-shaped" relationship between the transformation of ETM and the environmental pollution caused by different pollutants. In summary, the regression results are consistent with the previous benchmark regression results, indicating that the research results in this article are robust. At this time, the size of the three turning points has decreased to a certain extent, indicating that the lagging period of environmental pollution can explain a considerable part of the current environmental pollution, which leads to an earlier change in the current ETM.

\section{Table 5}

Replacement estimation method

\begin{tabular}{|c|c|c|c|}
\hline & $P M_{2.5}$ & $\operatorname{lnsO}_{2}$ & lnind-smoke \\
\hline & (1) & (2) & (3) \\
\hline \multirow[t]{2}{*}{ L.PM2.5 } & $0.8693^{* * *}$ & & \\
\hline & (0.0009) & & \\
\hline \multirow[t]{2}{*}{ L.lnso2 } & & $0.8298^{* * *}$ & \\
\hline & & $(0.0013)$ & \\
\hline \multirow[t]{2}{*}{ L.lnind-smoke } & & & $0.7994^{* * *}$ \\
\hline & & & $(0.0011)$ \\
\hline \multirow[t]{2}{*}{$T s$} & $0.1409^{* * *}$ & $0.0107^{* * *}$ & $0.0168^{* * *}$ \\
\hline & $(0.0071)$ & $(0.0007)$ & $(0.0004)$ \\
\hline \multirow[t]{2}{*}{$T s_{-} s q$} & $-0.0091^{* * * *}$ & $-0.0005^{* * *}$ & $-0.0007^{* * *}$ \\
\hline & $(0.0003)$ & $(0.0000)$ & $(0.0000)$ \\
\hline Observation & 3104 & 3104 & 3104 \\
\hline AR(2) P value & 0.299 & 0.222 & 0.212 \\
\hline Sargan $P$ value & 0.697 & 0.614 & 0.875 \\
\hline Turning point & 7.74 & 10.5 & 12 \\
\hline Control variables & Yes & Yes & Yes \\
\hline Year FE & Yes & Yes & Yes \\
\hline Urban FE & Yes & Yes & Yes \\
\hline
\end{tabular}

\subsection{Threshold effect test}

Because the threshold effect model is one of the common methods to deal with nonlinear relations, we use the threshold effect model to test the robustness in this part. Based on the research of Hansen (1999), this paper constructs a panel threshold model between transformation of ETM and environmental pollution: 


$$
\begin{aligned}
P M 2.5_{i t}= & \alpha+\theta_{1} T s_{i t} \times I\left(T s_{i t} \leq \delta_{1}\right)+\theta_{2} T s_{i t} \times I\left(\delta_{1}<T s_{i t} \leq \delta_{2}\right)+ \\
& \cdots+\theta_{n} T s_{i t} \times I\left(T s_{i t}>\delta_{n}\right)+\gamma X_{i t}+\mu_{i}+v_{t}+\zeta_{i t}
\end{aligned}
$$

Among them, $n$ represents the number of thresholds; Ts represents the threshold variable; $\delta$ is the threshold value with estimation; $I(\cdot)$ is the indicator function; $\theta$ is the influence coefficient of the explanatory variable in different intervals. Other variables are the same as above.

Based on the relevant literature and the threshold effect model, the transformation of ETM is used as the threshold variable to examine the degree of impact of ETM transformation on environmental pollution. In order to test the existence of the model threshold, the F statistic value, $\mathrm{P}$ value and threshold value of the threshold effect are calculated by Bootstrap method. The results are shown in part 1 of table 6 . The results show that when the explained variable is environmental pollution $\left(P M_{2.5}\right)$, the transformation of ETM has a double threshold effect on environmental pollution. Among them, the single threshold and the double threshold are significant at the statistical level of $1 \%$ and $10 \%$, and the triple threshold not obvious.

\section{Table 6}

\begin{tabular}{|c|c|c|c|c|c|c|}
\hline $\begin{array}{c}\text { Part1: Threshold } \\
\text { test }\end{array}$ & Threshold type & F Statistics & $\mathrm{P}$ value & $\begin{array}{c}\text { Threshold } \\
\text { value }\end{array}$ & $\begin{array}{c}\text { Lower } \\
\text { confidence } \\
\text { interval }\end{array}$ & $\begin{array}{c}\text { Upper } \\
\text { confidence } \\
\text { interval }\end{array}$ \\
\hline \multirow{3}{*}{$P M_{2.5}$} & Single threshold & 19.99 & 0.0067 & 1.8333 & 1.7291 & 1.8478 \\
\hline & Double threshold & 12.78 & 0.0833 & 1.8478 & 1.8478 & 1.8571 \\
\hline & Triple threshold & 7.11 & 0.54 & 1.11 & 1.1 & 1.125 \\
\hline \multirow{2}{*}{$\begin{array}{c}\text { Part2: Threshold } \\
\text { estimate }\end{array}$} & \multicolumn{6}{|c|}{$P M_{2.5}$} \\
\hline & \multicolumn{2}{|c|}{$T s<1.8333$} & \multicolumn{2}{|c|}{$1.8333<T s<1.8478$} & \multicolumn{2}{|c|}{$T s>1.8478$} \\
\hline \multirow[t]{2}{*}{$T s$} & \multicolumn{2}{|c|}{$-4.3649^{* * *}$} & \multicolumn{2}{|c|}{$-1.1265^{* *}$} & \multicolumn{2}{|c|}{$-0.0761^{* * *}$} \\
\hline & \multicolumn{2}{|c|}{$(0.9858)$} & \multicolumn{2}{|c|}{$(0.2331)$} & \multicolumn{2}{|c|}{$(0.0256)$} \\
\hline
\end{tabular}

Threshold regression test and regression results

Note: All Control variables, time and region fixed effects are controlled in the model.

After determining the threshold value, estimate the threshold effect model. Part 2 of table 6 reports the estimated results of the threshold effect model. The transformation of ETM has a significant threshold effect on environmental pollution (at least through the 5\% statistical level). When the transformation of ETM is lower than the threshold value of 1.8333 , the threshold coefficient is (-4.3649), indicating that the transformation of ETM has improved environmental pollution; when the transformation of ETM is between the threshold values $(1.8333,1.8478)$, the threshold coefficient is (-1.1265), The transformation of ETM significantly improves environmental pollution; when the transformation of ETM is higher than the threshold value of 1.8478 and the threshold coefficient is $(-0.0761)$, the transformation of ETM still significantly improves environmental pollution, but the degree of this effect is gradually weakened. It shows that appropriate transformation of ETM will help improve environmental pollution, but excessive changes in ETM may "backfire" and will weaken the effect of transformation of ETM on 
environmental pollution.

\section{3 \\ 5. Further discussion}

464

465

466

467

468

469

470

471

472

473

474

475

476

477

478

479

480

481

482

483

484

485

486

487

488

489

490

491

492

493

494

495

496

497

\subsection{Mechanism analysis}

From the previous $\mathrm{H} 2$, it can be seen that the transformation of ETM may affect environmental pollution through five ways: industrial structure upgrading effect, energy structure effect, industrial co-agglomeration effect, environmental protection investment effect, and resource allocation effect. Therefore, this section adopts the mediation effect model for estimate. Taking into account the nonlinear relationship between the transformation of ETM and environmental pollution, based on the research of Baron \& Kenny (1986), a mediating effect model that includes both the first and second terms of the explanatory variables is set up. The specific model is as follows:

$$
\begin{aligned}
& P M 2.5_{i t}=\alpha_{0}+c T s_{i t}+c_{1} T s_{-} s q_{i t}+\gamma X_{i t}+\mu_{i}+v_{t}+\zeta_{i t} \\
& M_{i t}=\alpha_{0}+a T s_{i t}+a_{1} T s_{-} s q_{i t}+\gamma X_{i t}+\mu_{i}+v_{t}+\zeta_{i t} \\
& P M 2.5_{i t}=\alpha_{0}+c^{\prime} T s_{i t}+c_{1}^{\prime} T s_{-} s q_{i t}+b M_{i t}+\gamma X_{i t}+\mu_{i}+v_{t}+\zeta_{i t}
\end{aligned}
$$

Among them, in formula (4), $M$ represents the intermediary variables. Including industrial structure update (update), energy consumption structure (energy), industrial co-agglomeration (coll), environmental protection investment (lneg), capital labor ratio $(\operatorname{lnkl})$; $T s, T s \_s q$ and $P M_{2.5}$ are the primary term, quadratic term and the explained variable $P M_{2.5}$ concentration value of ETM transformation, respectively. If the coefficients $c, a, c^{\prime}, c_{1}, a_{1}, c_{1}{ }^{\prime}$ and $b$ are significant, it means that the transformation of ETM has a mediating effect on environmental pollution. By comparing the turning point changes of equations (3) and (5): when the turning point becomes smaller, it indicates that the intermediary variable can accelerate the negative effect stage of ETM transformation on environmental pollution; and when the turning point becomes larger, it also shows that the intermediary variable will postpone the depressive effect of ETM transformation on environmental pollution. In short, the changes in the turning point of the nonlinear curve all prove that the intermediary variable plays an intermediary role in the process of ETM transformation and affecting environmental pollution.

\subsubsection{Industrial structure upgrading effect}

Based on the research of Gan et al. (2011), the paper uses the ratio of the output value of the secondary industry to the output value of the tertiary industry to measure upgrading level of industrial structure (update). Compared with the tertiary industry, the greater the proportion of the secondary industry, the more serious the pollution, which may cause a lot of environmental pollution during the development of the industry. Therefore, if the ratio drops, it indicates that the industrial structure is approaching "industrial greening", which will reduce environmental pollution. The industrialization process led by the secondary industry in China is an important factor in environmental pollution. At the same time, trade development can promote the optimization of industrial structure by promoting technological innovation and promoting consumer consumption. 
It can be seen that the transformation of ETM not only directly affects environmental pollution, but may also indirectly affect environmental pollution through optimizing the industrial structure. This part will focus on the analysis of the intermediary effect test of ETM transformation affecting environmental pollution. Table 7 reports the estimated results of the mediation effect based on the upgrading of industrial structure.

Regardless of the impact of the industrial structure, the results in column (1) show that the primary and quadratic coefficients of ETM transformation are positive and negative at the $1 \%$ statistical level respectively, indicating that there is an "inverted U-shaped" relationship between the transformation of ETM and environmental pollution, and the curve turning point value is 9.1519. Considering the influence of industrial structure, the results in column (3) show that the coefficient of industrial structure is significant at the $1 \%$ statistical level, and there is still an "inverted U-shaped" relationship between the transformation of ETM and environmental pollution, with a curve turning point value of 9.4515 . It can be seen that with and without considering the influence of industrial structure, the turning points of the "inverted U-shaped" curve of ETM transformation and environmental pollution are 9.4515 and 9.1519 , respectively, indicating that the effect of industrial structure upgrading will delay the transformation of ETM and have a negative impact on environmental pollution. To sum up, by optimizing the industrial structure and upgrading, and promoting the "green" transformation of the industry, it will help to promote the transformation of ETM and improve environmental pollution. $\mathrm{H} 2$ holds.

\section{Table 7}

Industrial structure upgrading effect

\begin{tabular}{cccc}
\hline & $P M_{2.5}$ & update & $P M_{2.5}$ \\
\cline { 2 - 4 } & $(1)$ & $(2)$ & $(3)$ \\
\hline \multirow{2}{*}{$T s$} & $0.2892^{* * *}$ & $0.0171^{* * *}$ & $0.3119^{* * *}$ \\
& $(0.0736)$ & $(0.0040)$ & $(0.0736)$ \\
& $-0.0158^{* * *}$ & $-0.0005^{* * *}$ & $-0.0165^{* * *}$ \\
update & $(0.0036)$ & $(0.0002)$ & $(0.0036)$ \\
& & & $-1.3292^{* * *}$ \\
constant & & & $(0.3273)$ \\
& $11.1832^{* *}$ & $-8.5156^{* * *}$ & -0.1359 \\
Observation & $(4.5046)$ & $(0.2474)$ & $(5.2876)$ \\
$R^{2}$ & 3298 & 3298 & 3298 \\
F test & 0.595 & 0.573 & 0.598 \\
Turning point & 174.2490 & 158.8689 & 169.2505 \\
Control variables & 9.1519 & - & 9.4515 \\
Year FE & Yes & Yes & Yes \\
Urban FE & Yes & Yes & Yes \\
\hline
\end{tabular}




\subsubsection{Energy structure effect}

According to the previous variable setting, the energy structure (energy) is used as the intermediary variable. Columns (1)-(3) of table 8 report the regression results of the impact of ETM transformation on environmental pollution through energy structures. The results of column (3) show that, as expected, the energy structure has a significant positive impact on environmental pollution, and the increase in the proportion of coal consumption will aggravate environmental pollution. The estimated coefficients of the primary and quadratic coefficients of ETM transformation are significantly positive and negative respectively, indicating that after the addition of intermediate variables, the relationship between the transformation of ETM and environmental pollution still shows an "inverted U-shaped" relationship of first promotion and then suppression. and compared with the model without intermediate variables in column (1), the turning point in column (3) is smaller. This means that the transformation of ETM is to reduce environmental pollution by optimizing the energy structure. Optimizing the energy structure will help to offset the energy consumed by pollution-intensive trade, reduce the difficulty of environmental pollution control, and improve the effectiveness of environmental control at the same time. $\mathrm{H} 2$ holds.

Table 8

Energy structure effect.

\begin{tabular}{|c|c|c|c|}
\hline & $P M_{2.5}$ & energy & $P M 2.5$ \\
\hline & (1) & (2) & (3) \\
\hline \multirow[t]{2}{*}{$T s$} & $0.2813^{* * * *}$ & $-0.0027^{*}$ & $0.2892^{* * *}$ \\
\hline & $(0.0737)$ & $(0.0015)$ & $(0.0736)$ \\
\hline \multirow[t]{2}{*}{$T s \_$sq } & $-0.0153^{* * *}$ & $0.0002^{* *}$ & $-0.0158^{* * *}$ \\
\hline & $(0.0036)$ & $(0.0001)$ & $(0.0036)$ \\
\hline \multirow[t]{2}{*}{ energy } & & & $2.9341^{* * *}$ \\
\hline & & & $(0.9068)$ \\
\hline \multirow[t]{2}{*}{ constant } & $13.1177^{* * *}$ & $0.6593^{* * *}$ & $11.1832^{* *}$ \\
\hline & $(4.4716)$ & $(0.0887)$ & $(4.5046)$ \\
\hline Observation & 3298 & 3298 & 3298 \\
\hline$R^{2}$ & 0.594 & 0.093 & 0.595 \\
\hline F test & 180.2459 & 12.5799 & 174.2490 \\
\hline turning point & 9.1928 & - & 9.1519 \\
\hline Control variables & Yes & Yes & Yes \\
\hline Year FE & Yes & Yes & Yes \\
\hline Urban FE & Yes & Yes & Yes \\
\hline
\end{tabular}

\subsubsection{Industrial co-agglomeration effect}

According to the formula (3)-(5), this part will test the intermediary effect of industrial coagglomeration, and the test results are shown in table 9. First of all, we draw lessons from the research of Cui et al. (2019) to calculate the industrial co-agglomeration index (coll). The specific 
formula is as follows:

$$
\operatorname{coll}_{i t}=1-\left|\operatorname{aggm}_{i t}-\operatorname{aggps}_{i t}\right| /\left(\operatorname{aggm}_{i t}+\operatorname{aggps}_{i t}\right)+\left(\operatorname{aggm}_{i t}+\operatorname{aggps}_{i t}\right)
$$

Among them, coll is the industrial co-agglomeration index, aggm represents the manufacturing agglomeration index, and aggps is the producer services agglomeration index. As far as the method of measuring the agglomeration index of producer services is concerned, this paper draws lessons from the research of Xuan et al. (2019). Four categories are selected to represent producer services: "financial industry", "scientific research, technical service and geological exploration industry", "information transmission, computer service and software industry", and "leasing and commercial service industry". The specific calculation formula is as follows:

$$
\operatorname{aggps}_{i t}=\sum_{\mathrm{s}}\left(E_{i s} / E_{s}\right) /\left(E_{i} / E\right)
$$

Among them, $E_{i s}$ represents the number of employees in the city $i$ producer services $S, E_{i}$ represents the number of employees in all industries in the city $i, E_{s}$ represents the number of employees in producer services $S$ in China, and $E$ represents the number of employees in all industries in China. If the index is larger, it means that the city has a higher degree of professional agglomeration of producer services. The calculation method of manufacturing agglomeration index is such as formula (7).

The results in column (2) of table 9 show that there is a "U-shaped" relationship between the transformation of ETM and industrial co-agglomeration, but it is not significant. In column (3), the significant level of industrial co-agglomeration is significantly negative, that is, the economies of scale, competition, specialization and technology spillover effects of industrial co-agglomeration can significantly improve environmental pollution (Cai et al., 2020). It shows that the transformation of ETM has an impact on environmental pollution through the intermediary variable of industrial co-agglomeration. In addition, from the results in column (3), we can see that the primary and quadratic coefficients of ETM transformation are still significant, indicating that the direct effect of ETM transformation on environmental pollution also exists. Comparing the turning point values of column (1) and column (3), it can be found that the turning point value decreases to a certain extent after adding industrial co-agglomeration, indicating that industrial co-agglomeration does have an intermediate effect between the transformation of ETM and environmental pollution. H2 holds.

\section{Table 9}

Industrial synergy and agglomeration effect.

\begin{tabular}{cccc}
\hline & $P M_{2.5}$ & coll & \multicolumn{1}{c}{$P M_{2.5}$} \\
\cline { 2 - 4 } & $(1)$ & $(2)$ & $(3)$ \\
\hline \multirow{2}{*}{$T s$} & $0.2879^{* * *}$ & $-0.0037^{*}$ & $0.2790^{* * *}$ \\
& $(0.0732)$ & $(0.0021)$ & $(0.0731)$ \\
$T s \_s q$ & $-0.0157^{* * *}$ & 0.0001 & $-0.0153^{* * *}$ \\
& & $(0.0001)$ & $(0.0036)$ \\
Incoll & & & $-2.4257^{* * *}$
\end{tabular}




\begin{tabular}{cccc} 
constant & $11.1820^{* * *}$ & $2.1998^{* * *}$ & $16.5182^{* * *}$ \\
& $(4.5045)$ & $(0.1298)$ & $(4.6993)$ \\
\hline Observation & 3298 & 3298 & 3298 \\
$R^{2}$ & 0.595 & 0.927 & 0.597 \\
F test & 174.2549 & $1.5 \mathrm{e}+03$ & 169.1295 \\
Turning point & 9.1688 & - & 9.1176 \\
Control variables & Yes & Yes & Yes \\
Year FE & Yes & Yes & Yes \\
Urban FE & Yes & Yes & Yes \\
\hline
\end{tabular}

\subsubsection{Investment effect of environmental protection}

The effective control of environmental pollution is inseparable from environmental protection investment. As one of the transformation ways of green development of export enterprises, the transformation of ETM can have a direct impact on environmental protection investment. Therefore, this part focuses on the environmental protection investment effect of ETM transformation. Based on the data of China Environmental Statistical Yearbook, the natural logarithm of investment in the treatment of industrial pollution sources is used to characterize the amount of investment in environmental protection. Table 10 reports the estimated intermediary effects based on environmental investment. The results of column (2) show that the quadratic term of ETM transformation is positive at the level of $10 \%$ significance, indicating that with the transformation of ETM, that is, in the process of changing from processing trade to general trade, export enterprises will gradually expand their investment in environmental protection. The results of column (3) listed as the empirical results of ETM transformation, environmental protection investment and environmental pollution, the results show that the coefficient of environmental protection investment and environmental pollution is significantly negative at $1 \%$ statistical level, indicating that environmental pollution can be significantly improved with the increase of environmental protection investment. In addition, there is still an "inverted U-shaped" relationship between the transformation of ETM and environmental pollution. To sum up, in the process of the impact of ETM transformation on environmental pollution, the investment effect of environmental protection has played a significant intermediary role. $\mathrm{H} 2$ holds.

\section{Table 10}

Investment effect of environmental protection.

\begin{tabular}{cccc}
\hline & $P M_{2.5}$ & lneg & $P M_{2.5}$ \\
\cline { 2 - 4 } & $(1)$ & $(2)$ & $(3)$ \\
\hline \multirow{2}{*}{$T s$} & $0.2930^{* * *}$ & -0.0061 & $0.2879^{* * * *}$ \\
& $(0.0734)$ & $(0.0056)$ & $(0.0732)$ \\
\multirow{2}{*}{$T s \_s q$} & $-0.0161^{* * *}$ & $0.0005^{*}$ & $-0.0157^{* * *}$ \\
& $(0.0036)$ & $(0.0003)$ & $(0.0036)$
\end{tabular}




\begin{tabular}{cccc} 
lneg & & & $-0.8379^{* * *}$ \\
constant & $13.0113^{* * *}$ & $-2.1831^{* * *}$ & $(0.2339)$ \\
& $(4.4841)$ & $(0.3448)$ & $11.1820^{* *}$ \\
\hline Observation & 3298 & 3298 & $(4.5045)$ \\
$R^{2}$ & 0.594 & 0.867 & 3298 \\
F test & 180.0198 & 805.2843 & 0.595 \\
Turning point & 9.0994 & - & 174.2549 \\
Control variables & Yes & Yes & 9.1688 \\
Year FE & Yes & Yes & Yes \\
Urban FE & Yes & Yes & Yes \\
\hline
\end{tabular}

\subsubsection{Resource allocation effect}

Reasonable allocation of resources will help to reduce the production cost of the enterprises. Export enterprises with high pollution and high energy consumption are abandoned by the market because of their low efficiency of resource allocation, thus reducing environmental pollution. In order to explore the internal mechanism of "resource-allocation effect of the ETM transformation", the Table 11 reports the estimated results of using resource allocation as an intermediate variable. In column (2) is the estimated result of the impact of ETM transformation on the allocation of resources, it can be seen that there is a significant "inverted U-shaped" relationship between the transformation of ETM and resource allocation, that is, with the transformation of ETM, it will have an impact on resource allocation that is promoted first and then suppressed. When considering the impact of ETM transformation and resource allocation on environmental pollution at the same time, the results in column (3) show that the estimated coefficient of resource allocation is positive at the significant level of $1 \%$. And the transformation of ETM also has a non-linear impact on environmental pollution, which means that with the transformation of ETM, environmental pollution can be reduced through the effect of resource allocation. In addition, by comparing the turning points in columns (1) and (3), it is found that the turning point after adding resource allocation has moved to the left. Accelerating the improvement of the efficiency of resource allocation of export enterprises will help to change the mode of export trade and reduce environmental pollution. $\mathrm{H} 2$ holds.

\section{Table 11}

Resource allocation effect.

\begin{tabular}{cccc}
\hline & $P M 2.5$ & $\operatorname{lnkl}$ & $P M 2.5$ \\
\cline { 2 - 4 } & $(1)$ & $(2)$ & $(3)$ \\
\hline$T S$ & $0.3166^{* * *}$ & $0.0086^{* * *}$ & $0.2879^{* * *}$ \\
& $(0.0734)$ & $(0.0023)$ & $(0.0732)$ \\
$T S$ s_sq & $-0.0168^{* * *}$ & $-0.0003^{* * *}$ & $-0.0157^{* * *}$ \\
& $(0.0036)$ & $(0.0001)$ & $(0.0036)$
\end{tabular}




\begin{tabular}{cccc} 
constant & $14.4849^{* * * *}$ & $0.9882^{* * * *}$ & $11.1820^{* * *}$ \\
& $(4.4906)$ & $(0.1381)$ & $(4.5045)$ \\
\hline Observation & 3298 & 3298 & 3298 \\
$R^{2}$ & 0.591 & 0.954 & 0.595 \\
F test & 178.0681 & 2558.24 & 174.2549 \\
Turning point & 9.4226 & - & 9.1688 \\
Control variables & Yes & Yes & Yes \\
Year FE & Yes & Yes & Yes \\
Urban FE & Yes & Yes & Yes \\
\hline
\end{tabular}

\subsection{Heterogeneity analysis}

In order to discuss the difference in the impact of ETM transformation on environmental pollution, this part will analyze the heterogeneity of the following three aspects: Firstly, according to regional division, the sample is divided into eastern, central, and western regions; Secondly, according to administrative divisions, that is, provincial capital cities and non-provincial capital cities.

Table 12 reports the estimated results of environmental pollution caused by the transformation of ETM in the eastern, central and western regions. According to the first three columns, for the eastern and central regions, the quadratic coefficient of ETM transformation is significantly negative at the statistical level of 5\%. It shows that there is a significant "inverted U-shaped" relationship between the transformation of ETM and environmental pollution in the eastern and central regions, that is, environmental pollution increases at first and then decreases with the transformation of ETM. In addition, after calculating the curve turning point values of the eastern and central regions are 5.6226 and 11.6492 respectively, compared with the turning point value of the whole sample curve 9.1519, it can be seen that in terms of the inhibitory effect stage of ETM transformation on environmental pollution, the eastern region will be ahead of the whole country, while the time point of the inhibitory effect stage in the central region lags behind that of the whole country. Different from the eastern and central regions, the primary and quadratic coefficients of ETM transformation in the western region are not significant, which means that there is no non-linear relationship between the transformation of ETM and environmental pollution in the western region. To sum up, there are significant differences in the impact of ETM transformation on environmental pollution in the eastern, central and western regions. The last two columns of estimates in Table 12 show that the transformation of ETM has a significant "inverted U-shaped" curve relationship with environmental pollution in both provincial capital city and non-provincial capital city.

\section{Table 12}

Analysis of regional heterogeneity. 


\begin{tabular}{cccccc}
\cline { 2 - 5 } & $\begin{array}{c}\text { Eastern } \\
\text { cities }\end{array}$ & $\begin{array}{c}\text { Central } \\
\text { cities }\end{array}$ & $\begin{array}{c}\text { Western } \\
\text { cities }\end{array}$ & $\begin{array}{c}\text { Provincial } \\
\text { capital city }\end{array}$ & $\begin{array}{c}\text { Non- } \\
\text { provincial } \\
\text { capital city }\end{array}$ \\
\cline { 2 - 6 } & $(1)$ & $(2)$ & $(3)$ & $(4)$ & $(5)$ \\
\hline$T s$ & 0.1788 & $0.2889^{* * *}$ & 0.1477 & $0.6172^{* * *}$ & $0.1801^{* *}$ \\
& $(0.1348)$ & $(0.1054)$ & $(0.1439)$ & $(0.1957)$ & $(0.0804)$ \\
$T s \_s q$ & $-0.0159^{* *}$ & $-0.0124^{* *}$ & -0.0048 & $-0.0276^{* * *}$ & $-0.0114^{* * *}$ \\
& $(0.0068)$ & $(0.0051)$ & $(0.0072)$ & $(0.0099)$ & $(0.0039)$ \\
constant & $-15.3393^{* *}$ & $41.1376^{* * *}$ & 7.3157 & -17.1899 & $16.1770^{* * *}$ \\
& $(6.2301)$ & $(8.3505)$ & $(11.4634)$ & $(15.1427)$ & $(4.7492)$ \\
\hline Observation & 1428 & 1343 & 527 & 509 & 2789 \\
$R^{2}$ & 0.666 & 0.648 & 0.539 & 0.507 & 0.616 \\
F test & 101.2796 & 87.6558 & 21.1456 & 17.9093 & 160.5754 \\
Turning point & 5.6226 & 11.6492 & - & 11.1812 & 7.8991 \\
Control variables & Yes & Yes & Yes & Yes & Yes \\
Year FE & Yes & Yes & Yes & Yes & Yes \\
Urban FE & Yes & Yes & Yes & Yes & Yes \\
\hline
\end{tabular}

639

\section{Main conclusions and policy suggestions}

Based on the panel data of 194 cities in China from 2000 to 2016, this paper investigates the influence of ETM transformation on environmental pollution and its internal mechanism. The main conclusions are as follows: There is a significant "inverted U-shaped" relationship between the transformation of ETM and environmental pollution, and after the transformation of ETM exceeds the turning point, it will show a significant inhibitory effect on environmental pollution; The threshold effect model test results show that there are double threshold effects in the transformation of ETM; After a series of robustness tests, such as substitution of variables, lag effect and SYSGMM estimation, the research conclusion is still valid; The results of heterogeneity test show that the transformation of ETM and environmental pollution in the eastern and central regions show a significant "inverted U-shaped" relationship; The impact of ETM transformation on environmental pollution has strong heterogeneity in different time periods. Mechanism analysis shows that industrial structure, energy structure, industrial synergy, environmental protection investment and resource allocation are the main ways for the transformation of export trade mode to affect environmental pollution.

Although trade development can promote the high-quality development of China's economy, it should attach great importance to environmental pollution control. Through analysis, we come to the following four policy recommendations:

Firstly, from the perspective of the government. Formulate practical trade policies, the transformation of ETM, and guide domestic enterprises to actively undertake clean production links with high profits and low energy consumption when participating in global value division through 
policies, so as to avoid pursuing economic interests to undertake production links with serious pollution discharge. Guide processing trade enterprises to achieve green transformation and upgrading, take the road of intensive and green production, make full use of domestic and international market resources, pay attention to scientific research, and develop advanced production technologies and environmental pollution control technologies under the new development pattern of double circulation; Reasonable control of processing trade activities to avoid the negative effects of excessive processing trade on environmental pollution. In addition, the government should provide environmental protection subsidies to Chinese export enterprises to encourage green development.

Secondly, based on the regional perspective. In the process of ETM transformation and improving environmental pollution, it is reasonable to make overall plans for the development of different regions, and the eastern and central regions should play a leading role in promoting trade development and effective environmental governance, and strengthen inter-regional cooperation and exchanges; Pay attention to technological innovation while trade development promotes economic growth; The western region needs to strengthen the intensity of environmental control when undertaking the industrial transfer in the eastern region, and the local government should reasonably coordinate enterprises to realize the benign development of trade.

Thirdly, based on the industrial perspective. Encourage the co-agglomeration of producer services and manufacturing industries. On the one hand, promote Chinese export trade enterprises to enhance their production technology innovation capabilities, transform green production methods, and improve the competitiveness of green products. On the other hand, research and develop advanced environmental treatment technologies to improve China's environmental pollution. Vigorously promote the development of producer services, actively change the export trade mode, make it organically integrate with producer services, and realize their common development. Actively advocate the development of green finance, derive diversified financial products, increase green investment, make it an important part of the development strategy of Chinese export enterprises, promote the green process of enterprises, and improve the environmental quality.

Fourthly, from the perspective of enterprises. Export enterprises should focus on the transformation of export trade mode while expanding the scale of trade. Through the technology spillover effect of upstream and downstream foreign enterprises, the level of their own production technology innovation is continuously improved, and the traditional extensive trade mode is gradually transformed into a green trade mode to reduce environmental pollution.

\section{References:}

Al-mulali, U. (2012). Factors affecting CO2 emission in the Middle East: A panel data analysis. Energy, 44(1), 564-569.

Al-Mulali, U., Saboori, B., \& Ozturk, I. (2015). Investigating the environmental Kuznets curve hypothesis in Vietnam. Energy policy, 76, 123-131. 
Asiedu, B. A., Gyamfi, B. A., \& Oteng, E. (2021). How do trade and economic growth impact environmental degradation? New evidence and policy implications from the ARDL approach. Environmental Science and Pollution Research, 1-9.

Baron, R. M., \& Kenny, D. A. (1986). The moderator-mediator variable distinction in social psychological research: Conceptual, strategic, and statistical considerations. Journal of personality and social psychology, 51(6), 1173.

Cai H, Xu Y, \& Zhao Y. (2020). Industrial agglomeration, manufacturing efficiency and smog pollution. Journal of China University of Geosciences (Social Science Edition) .20 (2), 60-73.

Chien, F., Anwar, A., Hsu, C. C., Sharif, A., Razzaq, A., \& Sinha, A. (2021). The role of information and communication technology in encountering environmental degradation: Proposing an SDG framework for the BRICS countries. Technology in Society, 65, 101587.

Copeland, B. R., \& Taylor, M. S. (1994). North-South trade and the environment. The quarterly journal of Economics, 109(3), 755-787.

Cui S, Li G, \&Dou J. (2019). Research on the Mismatch Effect of Industrial Synergy. Statistical Research, 36(2), 76-87.

Dean, J. M. (2002). Does trade liberalization harm the environment? A new test. Canadian Journal of Economics/Revue canadienne d'économique, 35(4), 819-842.

Essandoh, O. K., Islam, M., \& Kakinaka, M. (2020). Linking international trade and foreign direct investment to $\mathrm{CO} 2$ emissions: any differences between developed and developing countries? Science of the Total Environment, 712, 136437.

Figueiredo, R., \& de Matos Ferreira, J. J. (2020). Spinner model: prediction of propensity to innovate based on knowledge-intensive business services. Journal of the Knowledge Economy, 11(4), 1316-1335.

Gan C, Zheng R, \&Yu D. (2011). The Impact of China's Industrial Structure Change on Economic Growth and Fluctuation. Economic Research, 46(5), 4-16+31.

Grossman, G. M., \& Rossi-Hansberg, E. (2008). Trading tasks: A simple theory of offshoring. American Economic Review, 98(5), 1978-97.

Hansen, B. E. (1999). Threshold effects in non-dynamic panels: Estimation, testing, and inference. Journal of econometrics, 93(2), 345-368.

He, L. Y., Lin, X., \& Liu, Q. (2020). How did free trade reshape the transitional China? Evidence from heterogeneous exporters and firm-level pollution emissions. Emerging Markets Finance and Trade, 56(8), 1651-1676.

Jun, W., Mughal, N., Zhao, J., Shabbir, M. S., Niedbała, G., Jain, V., \& Anwar, A. (2021). Does globalization matter for environmental degradation? Nexus among energy consumption, economic growth, and carbon dioxide emission. Energy Policy, 153, 112230.

Khan, I., Hou, F., Le, H. P., \& Ali, S. A. (2021). Do natural resources, urbanization, and valueadding manufacturing affect environmental quality? Evidence from the top ten manufacturing countries. Resources Policy, 72, 102109.

Kim, D. H., Suen, Y. B., \& Lin, S. C. (2019). Carbon dioxide emissions and trade: Evidence from 
disaggregate trade data. Energy Economics, 78, 13-28.

Koyuncu, T., Beşer, M. K., \& Alola, A. A. (2021). Environmental sustainability statement of economic regimes with energy intensity and urbanization in Turkey: a threshold regression approach. Environmental Science and Pollution Research, 1-14.

Li G, Li L, Li X, et al. (2021). Can the establishment of National Key Ecological Functional Zones improve air quality? An empirical study from China. PloS one, 2021, 16(2): e0246257.

Li G, Li L, Liu D, et al. (2021). Effect of PM 2.5 pollution on perinatal mortality in China. Scientific Reports, 2021, 11(1): 1-12.

Lin B \& Liu H. (2015). Is foreign trade conducive to improving energy and environmental efficiency?-Taking China's industrial sector as an example. Economic Research, 50(9), 127-141.

Melitz, M. J. (2003). The impact of trade on intra - industry reallocations and aggregate industry productivity. econometrica, 71(6), 1695-1725.

Sabir, S., Qayyum, U., \& Majeed, T. (2020). FDI and environmental degradation: the role of political institutions in South Asian countries. Environmental Science and Pollution Research, 27(26), 32544-32553.

Shahbaz, M., Lean, H. H., \& Shabbir, M. S. (2012). Environmental Kuznets curve hypothesis in Pakistan: cointegration and Granger causality. Renewable and Sustainable Energy Reviews, $16(5), 2947-2953$.

Shahbaz, M., Nasreen, S., Ahmed, K., \& Hammoudeh, S. (2017). Trade openness-carbon emissions nexus: the importance of turning points of trade openness for country panels. Energy Economics, $61,221-232$.

Shao S, Li X, \& Cao Jianhua. (2019). Urbanization and Smog Control in China. Economic Research, 54(2), 148-165.

Shao S, Li X, Cao J, \& Yang L. (2016). Economic Policy Choice of Smog Pollution Control in China — From the Perspective of Spatial Spillover Effect. Economic Research, 51(9), 73-88.

Shi D, Ding H, Wei P, \& Liu J. (2018). Can smart city construction reduce environmental pollution. China Industrial Economy, 6, 117-135.

Sun C, Qin Q, \& Wang S. (2021). Does the performance of urban center promote the upgrading of urban export structure? Evidence from Chinese cities and urban agglomerations. World Economic Research, 4(01), 17-31+134.

Xie, Q., \& Liu, J. (2019). Combined nonlinear effects of economic growth and urbanization on CO2 emissions in China: evidence from a panel data partially linear additive model. Energy, 186, 115868.

Xie, Q., \& Wu, H. (2021). How does trade development affect environmental performance? New assessment from partially linear additive panel analysis. Environmental Impact Assessment Review, 89, 106584.

$\mathrm{Xu}, \mathrm{B} .$, \& Lin, B. (2015). How industrialization and urbanization process impact on $\mathrm{CO} 2$ emissions in China: evidence from nonparametric additive regression models. Energy Economics, 48, 188202. 
777

Xuan Y, Lu J, \&Yu Y. (2019). Influence of the opening of high-speed rail on the spatial agglomeration of high-end service industry. Finance and Trade Economics, 40(9), 117-131.

Ye, Y., Khan, Y. A., Wu, C., Shah, E. A., \& Abbas, S. Z. (2021). The impact of financial development on environmental quality: evidence from Malaysia. Air Quality, Atmosphere \& Health, 1-14.

Yi, K. M. (2003). Can vertical specialization explain the growth of world trade? Journal of political Economy, 111(1), 52-102.

Yu, C., Nataliia, D., Yoo, S. J., \& Hwang, Y. S. (2019). Does trade openness convey a positive impact for the environmental quality? Evidence from a panel of CIS countries. Eurasian Geography and Economics, 60(3), 333-356.

Zafar, M. W., Qin, Q., \& Zaidi, S. A. H. (2020). Foreign direct investment and education as determinants of environmental quality: The importance of post Paris Agreement (COP21). Journal of Environmental Management, 270, 110827. 